\title{
Marssonina coronaria, NUEVO AGENTE CAUSAL DE MANCHAS FOLIARES EN MANZANOS DE BAJOS REQUERIMIENTOS DE FRIO DEL CENTRO DE ARGENTINA
}

\author{
Fernandez, L. ${ }^{1,2} ;$ Berutti, G. ${ }^{1} ;$ Gariglio, N. ${ }^{2}$; \\ FAVARO, M. A. ${ }^{1,2}$ \& MAUMARY, R. ${ }^{1}$
}

\begin{abstract}
RESUMEN
Durante los años 2017-2018, una enfermedad fúngica causó una importante defoliación temprana en manzanos de los cvs 'Caricia', 'Princesa' y 'Eva' del centro-este de la Provincia de Santa Fe. La sintomatología fue coincidente con la reportada para Marssonina spp. Con el objetivo de caracterizar la etiología de la enfermedad se obtuvieron 9 aislados, siendo 4 caracterizados morfométrica y molecularmente. Luego de 60 días, las colonias alcanzaron $10 \mathrm{~mm}$ de diámetro, con márgenes irregulares y coloración marrón. Los conidios, hialinos, ligeramente curvos, ovoides y bi-celulares midieron 15,23 $\pm 1,49 \mu \mathrm{m}$ de largo y 5,47 $\pm 0,52 \mu \mathrm{m}$ de ancho. Las secuencias de ITS indicaron $100 \%$ de identidad con Marssonina coronaria. Se confirmó la patogenicidad de los aislados. Todas las inoculaciones produjeron síntomas y el patógeno fue re-aislado coincidiendo sus características con las inicialmente mencionadas. Este estudio constituye el primer reporte de $M$. coronaria afectando hojas de manzano en Argentina y proporciona información útil para diseñar estrategias de manejo.
\end{abstract}

Key words: Marssonina coronaria, defoliación, Manzanos de bajo requerimiento de frío, Santa Fe.

1.- Departamento de Producción Vegetal. Facultad de Ciencias Agrarias (UNL). Kreder 2805. (3080HOF) Esperanza, provincia de Santa Fe, Argentina. Email: laurafernandez1@gmail.com

2.- Instituto de Ciencias Agropecuarias del Litoral. UNL-CONICET-FCA. Kreder 2805. (3080HOF) Esperanza, provincia de Santa Fe, Argentina.

Manuscrito recibido el 9 de octubre de 2019 y aceptado para su publicación el 2 de diciembre de 2020.

Fernandez, L; Berutti, G.; Gariglio, N.; Favaro, M.A. \& Maumary, R. Marssonina coronaria, nuevo agente causal de manchas foliares en manzanos de bajos requerimientos de frío del centro de Argentina. FAVE Ciencias Agrarias 19 (1): 43-53. CC BY-NC-SA 4.0 (1) (1) 


\begin{abstract}
Marssonina coronaria, new causal agent of leaf spots in apple trees with low chilling requirements in central Argentina.

During 2017-2018 years, a fungal disease caused significant early defoliation on cvs 'Caricia', 'Princesa' and 'Eva' apples trees in the center-east of the Province of Santa Fe. The symptomatology was consistent with that reported for Marssonina spp. With the purpose of characterizing the etiology of the disease, 9 isolates were obtained; being 4 characterized morphometrically and molecularly. After 60 days, the colonies reached $10 \mathrm{~mm}$ in diameter, with irregular margins and brown coloration. Conidia were hyaline, slightly curved, obovoid, unequally two-celled. The size was $15.23 \pm 1.49 \mu \mathrm{m} \times 5.47 \pm 0.52 \mu \mathrm{m}$. The isolates were identified with $100 \%$ identity as Marssonina coronaria based on ITS gene phylogenetic analyses. The pathogenicity of the isolates was confirmed. All inoculations produced symptoms and the pathogen was re-isolated, corresponding its characteristics with those initially mentioned. This study is the first report of $M$. coronaria affecting apple leaves in Argentina and provides useful information to design management strategies.
\end{abstract}

Key words: Marssonina coronaria, defoliation, low-chilling apple, Santa Fe.

\section{INTRODUCCIÓN}

En Argentina, las exigencias de frío de las plantas de manzanas, hacen que las zonas tradicionales de cultivo sean principalmente las Provincias de Neuquén y el Valle de Río Negro (Patagonia Norte), concentrando éstas el 80\% de la producción (7). La provincia de Santa Fe, si bien presenta baja importancia relativa dentro del mapa frutícola del país, ha incorporado en su producción cultivares de manzanos de bajos requerimientos de frío (6) que han demostrado un comportamiento productivo positivo (10).

Sin embargo, desde el año 2011 la producción de manzanas ha atravesado distintas problemáticas fitosanitarias, dentro de las que se registran muerte de plantas por Botryosphaeria dothidea (26), podredumbre amarga por Colletotrichum siamense (8) y podredumbre de frutos por Botryos- phaeria sp. En el año 2017, en plantaciones de los cvs 'Caricia' (IAPAR 77; 'Anna' $\times$ 'Prima'), 'Princesa' ('Anna' $\times$ 'NJ56') y 'Eva' (IAPAR 75; 'Anna' × 'Gala') se observó una defoliación temprana que comenzó desde mediados de noviembre. Las características de la sintomatología observada a campo coincidieron con aquellas citadas para Marssonina spp. (2, 3, 17, 28, 33).

La mancha foliar por Marssonina es la enfermedad más severa conocida en manzanos $(2,19,20)$. Reportes existentes para India indican que los brotes epidémicos se producen con temperaturas de $20{ }^{\circ} \mathrm{C}$ y $100 \%$ de humedad relativa además de un período de humedad en la hoja de $40 \mathrm{~h}$ (29). Trabajos de Lee et al., (19) en Korea y Goyal et al., (11) en Imachal Pradesh (Estado de India) confirman los resultados. Esta enfermedad es causada por el hongo Diplocarpon mali (Y. Harada y K. Sawamura [anamorfo Marssonina coronaria 
(Ellis y J. J. Davis) J.J. Davis, sinónimo $M$. mali (Henn.) S. Ito]). Está ampliamente distribuida a nivel mundial y fue reportada en países como Corea y China, en América del Norte, y en países de Europa, provocando defoliaciones de hasta el $87 \%$ que se traducen en importantes pérdidas económicas, reduciendo a largo plazo el vigor de los árboles; afectando el inicio de la floración siguiente y consecuentemente la cantidad y calidad de la fruta $(12,19,20,33)$. Las lesiones típicas de este patógeno se caracterizan por manchas foliares de color pardo oscuro y en correspondencia pequeñas acérvulas negras en la superficie de la hoja. A medida que la enfermedad progresa las manchas coalescen y se tornan oscuras; posteriormente las hojas se vuelven amarillas y se caen (30). Este patógeno se propaga por el agua (lluvia, riego por aspersión) y la germinación de los conidios requiere una humedad relativa alta, 92\% o más, durante un tiempo mínimo de seis horas.

En Argentina no hay registros de éste patógeno para plantaciones de manzanos; así los reportes existentes para Marssonina se limitan a hojas, estolones y pecíolos de frutilla (Marssonina fragariae) (9); hojas de rosa sp (Marssonina rosae) en Corrientes y Noroeste Argentino (4, 5, 34), hojas y ramas de sauce álamo; hojas de Sauce llorón (Marssonina salicicola), y hojas de Sauce híbrido (Marssonina kriegeriana) en el Delta del Paraná (9).

El objetivo de este trabajo fue caracterizar la etiología del agente causal mediante identificación taxonómica tradicional y molecular de la especie presente en la región centro-este de Santa Fe.

\section{MATERIALES Y MÉTODOS}

\section{Obtención de aislados y condiciones de cultivo}

El trabajo se llevó a cabo en el Campo Experimental de Cultivos Intensivos y Forestales (CECIF) de la Facultad de Ciencias Agrarias de la Universidad Nacional del Litoral en la localidad de Esperanza, Santa Fe $\left(60^{\circ} 50^{\prime} \mathrm{O}, 31^{\circ} 25^{\prime} \mathrm{S}\right)$. Durante dos años (2017-2018) se recolectaron hojas con sintomatología de manchas foliares de plantas de 15 años de edad. Se trabajó con los cvs 'Caricia', 'Princesa' y 'Eva' injertadas sobre pie "M.9", bajo una densidad de plantación de 1250 plantas por hectárea, sobre suelo argiudol típico.

Los aislamientos fueron obtenidos a partir de fragmentos (3-5mm) de lesiones con presencia de acérvulas, que previamente se desinfectaron en $1 \%$ de $\mathrm{NaOCl}$ (hipoclorito de sodio) durante $2 \mathrm{~min}$, para eliminar saprofitos, seguido de tres enjuagues con agua destilada estéril (ADE). Los fragmentos se sembraron en medio de cultivo agar agua (AA) y se incubaron en la oscuridad a $20^{\circ} \mathrm{C}$ durante dos semanas. Los conidios producidos se extrajeron en ADE y $1 \mathrm{~mL}$ de la suspensión se esparció mediante espátula de Drigalsky en una placa con AA. Luego se incubaron en oscuridad a $20 \pm$ $1{ }^{\circ} \mathrm{C}$ durante dos días, un conidio germinado se transfirió a una placa con $\underline{\text { Agar }}$ Papa Dextrosa (APD) enmendado con sulfato de estreptomicina 0,5 g.L-1 (19). Los cultivos monospóricos obtenidos se conservaron en papel de filtro a $-20^{\circ} \mathrm{C}$ y $\mathrm{ADE}$ a $25^{\circ} \mathrm{C}$ para futuras experiencias/ensayos. 
Caracterización morfométrica de colonias

Colonias de 50-60 días de crecimiento en APD se caracterizaron morfológicamente por medio de la observación macroscópica, evaluando color y características del micelio, tinción del medio de cultivo y tamaño. Microscópicamente se observó la forma, color de los conidios y presencia de estado sexual o teleomorfo. Mediante el programa Image $\mathrm{J}$ se midió largo y ancho de 50 conidios por aislado y se compararon los resultados con la bibliografía existente.

\section{Extracción de ADN; amplificación mediante PCR y secuenciación}

Para realizar la identificación molecular, se obtuvo el ADN de 4 aislamientos a partir de colonias crecidas en medio APD a $20^{\circ} \mathrm{C}$ en oscuridad durante 60 días. Para tal fin se utilizó un protocolo de extracción de ADN de rutina (19). Posteriormente se amplificó, mediante la técnica de reacción en cadena de la polimerasa (PCR), la región ITS (del inglés "internal transcribed spacer") del ADN nuclear ribosomal (rDNA) utilizando los cebadores universales ITS4 (5'-TCC TCC GCT TAT TGA TAT GC-3') / ITS5 (5'-GGAAGTAAAAGTCGTAACAAGG-3') (32). Todas las amplificaciones se llevaron a cabo en un termociclador Techne TC-312 con un volumen de reacción de 20 $\mu \mathrm{L}$ por muestra. La mezcla de PCR contenía $1 \times$ PCR buffer, $2,5 \mathrm{mM} \mathrm{MgCl}, 0,4$ $\mu \mathrm{M}$ de cada primer, $0,2 \mathrm{mM}$ dNTPs, $1 \mathrm{U}$ of Taq DNA polymerase (PB-L, Productos Bio-Lógicos $\left.{ }^{\circledR}\right)$ y 100 ng de ADN genómico. La amplificación se llevó a cabo con una temperatura inicial de desnaturalización de $94^{\circ}$ durante 5 min seguido por 34 ciclos de: $94^{\circ} \mathrm{C}$ durante $30 \mathrm{seg}, 55^{\circ} \mathrm{C}$ durante $30 \mathrm{seg}$ y $72^{\circ} \mathrm{C}$ durante $30 \mathrm{seg}$. El ciclo de extensión final fue de $72^{\circ} \mathrm{C}$ durante $7 \mathrm{~min}$. Los productos de PCR se corrieron en un gel de agarosa al 1,5\%, se tiñeron con GelRed ${ }^{\mathrm{TM}}$ (Biotium) y se visualizaron con luz ultravioleta (UV) en un transiluminador BIO View UST-30M-8E. Wavelength $312 \mathrm{~nm}$ (Germany). Las amplificaciones que fueron positivas se purificaron y secuenciaron en un 3730 XL DNA Analyzer (Applied Bio-systems ${ }^{\circledR}$ ) en Macrogen (Seoul, Corea). Las secuencias obtenidas fueron evaluadas mediante el programa Molecular Evolutionary Genetic Analysis (MEGA X) para posteriormente compararlas con las disponibles en la base de datos pública de GenBank (National Center for Biotechnology Information, NCBI) utilizando la herramienta BLAST.

\section{Pruebas de patogenicidad}

Se realizaron pruebas de patogenicidad en hojas de manzanas de los mismos cultivares de los cuales los aislamientos fueron extraídos. Para lograr el inóculo se utilizaron colonias de 60 días creciendo en APD siguiendo la técnica de Yin et al., (36) ajustando la suspensión a una concentración de $1 \times 10^{6}$ conidios $\mathrm{mL}^{-1}$. Para el ensayo, un conjunto de ramas terminales jóvenes con 5-6 hojas se desinfectaron con hipoclorito de sodio $8 \%$ por 10 minutos y se plantaron individualmente en contenedores de vidrio con arena húmeda. Las hojas se inocularon rociando $15 \mathrm{~mL}$ de la suspensión de conidios. Se cubrieron inmediatamente con una bolsa de plástico humedecida (1) y se incubaron en cámara de crecimiento a $20 \pm$ $1^{\circ} \mathrm{C}$ y 12 horas de luz evaluando periódicamente la producción de síntomas. Se inocularon 5 ramas por aislamiento y 5 ramas fueron rociadas con ADE como control. Para completar los postulados de Koch, el 
microorganismo se re aisló de las lesiones generadas a partir de la inoculación y sus características se compararon con las inicialmente registradas.

\section{RESULTADOS Y DISCUSIÓN}

En los años de estudio se registraron diferentes lesiones foliares que se iniciaron a mitad de primavera y principios de verano. Algunas eran compatibles con antracnosis, cuyo agente causal se identificó como Colletotrichum spp.; otras eran lesiones redondeadas con presencia de tejido necrótico, cuyo agente causal se determinó como Alternaria spp. y las de mayor relevancia fueron lesiones necróticas, pequeñas, a veces como puntos aislados y otras como manchas difusas aracnoides, irregulares aisladas o confluentes, de color pardo, en ocasiones rodeadas de un halo rojizo y que con el tiempo provocaban amarilleo y caída de las hojas. Las características distintivas que presentaban estas lesiones fue que rara vez su efecto se hacía notorio en la parte abaxial de la hoja, presentándose las manchas sólo en la cara adaxial. Sobre estas lesiones la mayoría de las veces fueron visibles pequeños puntos oscuros (como cabezas de alfileres) constituídos por acérvulas subcuticulares errumpentes, liberando una masa color blanco de conidios (Fig. 1). Para identificar al agente causal de esta sintomatología se obtuvieron muestras que fueron llevadas al laboratorio para su estudio.

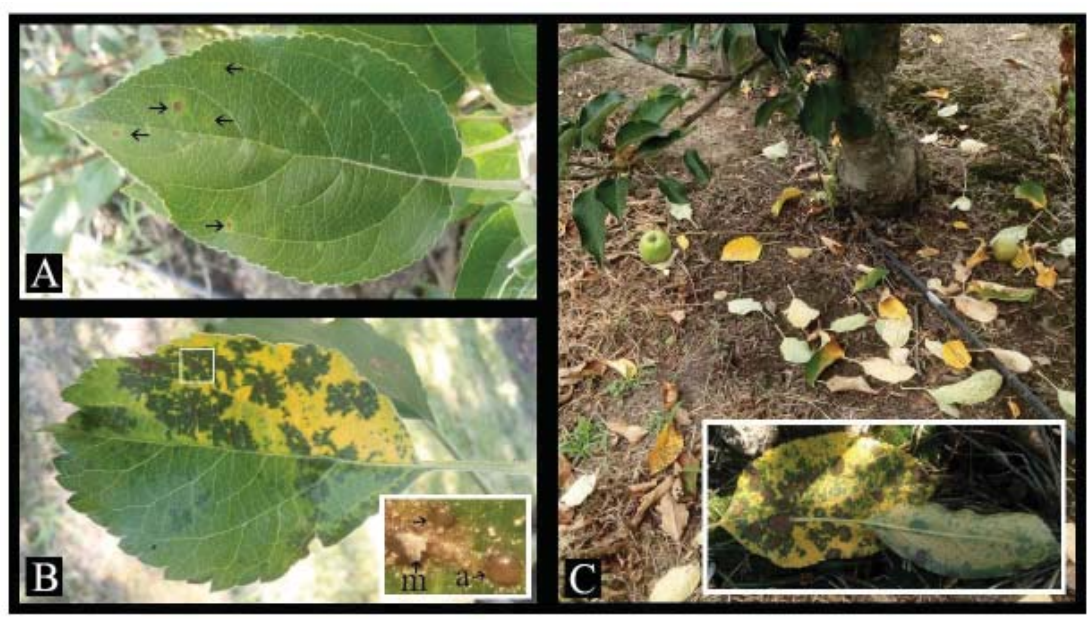

Figura 1: Síntomas de etiología desconocida observados en el campo. A) Hoja con lesiones iniciales observados la primera semana de noviembre, B) Hoja con lesiones y amarilleo característico observados a mediados de diciembre. En el recuadro ampliado se muestran las acérvulas (a) inmaduras y masa de conidios (m), C) Defoliación en árbol de manzano infectado. En el recuadro ampliado se observa en detalle las hojas infectadas, las lesiones necróticas son visibles solo en el haz de la misma. 


\section{Caracterización morfométrica y molecular de aislados}

A partir de las lesiones previamente descriptas, se obtuvieron 9 aislados (tres de cada cv. de manzano) con características del género Marssonina spp. Éstos no presentaron diferencias en sus aspectos morfotaxonómicos por lo que se seleccionaron al azar 4 (E, P21, C, C12) para las diferentes evaluaciones. Este hongo es particularmente difícil de cultivar in vitro porque crece muy lentamente en medios artificiales, lo que aumenta la probabilidad de contaminaciones $(12,19)$. Así, luego de 60 días de incubación a $20 \pm 1^{\circ} \mathrm{C}$, las colonias alcanzaron hasta $10 \mathrm{~mm}$ de diámetro y 1-5 $\mathrm{mm}$ de alto, con márgenes irregulares, de color marrón claro y centro de color pardo oscuro, conformado por una masa compacta de conidios. El micelio se veía inmerso, semi-hialino y septado. Cuando las colo- nias empezaban a envejecer se tornaban color marrón oscuro - negro y con aspecto arrugado en su superficie. Los conidios observados en todos los aislamientos fueron hialinos, ligeramente curvados, ovoides, bi-celular con diferencias de tamaño entre una célula y otra, ocasionalmente se observaron conidios con tres células. La célula superior generalmente era de mayor tamaño y la inferior más atenuada en su base y con un ápice trunco (Fig. 2). Además pudo observarse entre uno y tres núcleos dentro de cada célula. El valor medio del largo y ancho de los conidios fue 15,23 $\pm 1,49 \mu \mathrm{m}$ $(11,66-18,87 \mu \mathrm{m})$ y $5,47 \pm 0,52 \mu \mathrm{m}(4,39$ $6,53 \mu \mathrm{m})$. Todas estas características morfológicas de las colonias y conidios del hongo son consistentes con las reportadas para $M$. coronaria, teleomorfo Diplocarpon mali $(12,13,15,19,20,28,29,31,37)$.

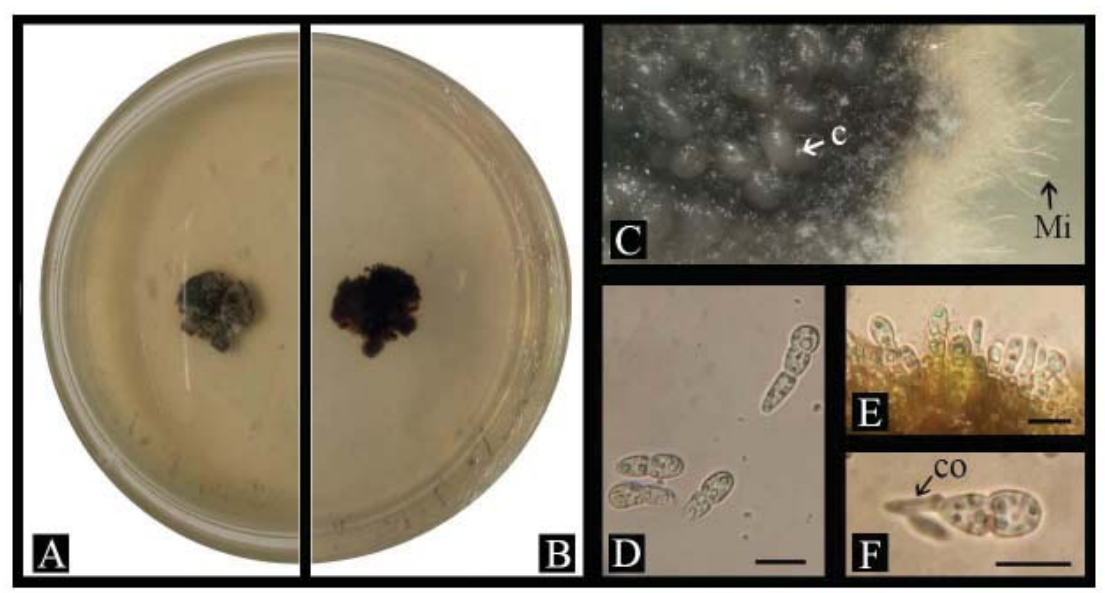

Figura 2: Características morfométricas de colonia de M. coronaria luego de 60 días creciendo en APD; A-B) Colonias de frente y de revés, respectivamente. Colonia de superficie de aspecto rugoso, de color marrón oscuro con escaso micelio aéreo; de bordes irregulares y sin tinción del medio de cultivo; C) Detalle de los bordes de la colonia mostrando masa de conidios (c) y avance del micelio (Mi); D) Conidios hialinos con dos y tres células, constreñidas en el tabique; E) Acérvula; F) Conidio con conidióforo (co). Barras de escalas $=10 \mu \mathrm{m}$. 
Las regiones de ITS amplificadas para los primers ITS4/ITS5 rondaron los $525 \mathrm{pb}$. Los resultados de BLAST revelaron 100\% de identidad con la secuencia de $M$. coronaria Henn (Forma perfecta Diplocarpon mali Harada \& Sawamura) disponible en NCBI (código de acceso AB609191). Las secuencias fueron depositadas en la base de datos de nucleótidos de NCBI bajo los números de acceso de GenBank MN535179, MN535180; MN535181 y MN535182. Estas regiones génicas ya han sido utilizadas con éxito por Lee et al., (19) para identificar a Marssonina coronaria afectando plantaciones de manzanos de Gyeongbuk (Korea) y por Phurailatpam et al., (24) para manzanos de Himachal Pradesh (India) y han demostrado el potencial de las secuencias para la determinación de especies.

\section{Pruebas de patogenicidad}

Identificado el patógeno, se realizaron las pruebas de patogenicidad para confirmar que el hongo aislado era el que realmente estaba causando esa defoliación temprana. Como puede observarse en la Figura 3, los aislados fueron capaces de producir las lesiones típicas de Marssonina spp. Los síntomas iniciales; manchas necróticas pequeñas (4-6 mm) color marrón oscuro, a veces rodeadas de un halo color rojizo; se observaron a los 15 días post inoculación (dpi). A medida que la infección progresaba, las lesiones crecieron en diámetro y empezaron a coalescer tornándose oscuras e irregulares. Sobre las lesiones más viejas se desarrollaron acérvulas en la parte central del tejido necrosado. Las hojas del grupo control se mantuvieron sanas hasta el final del ensayo. Estos resultados sugieren

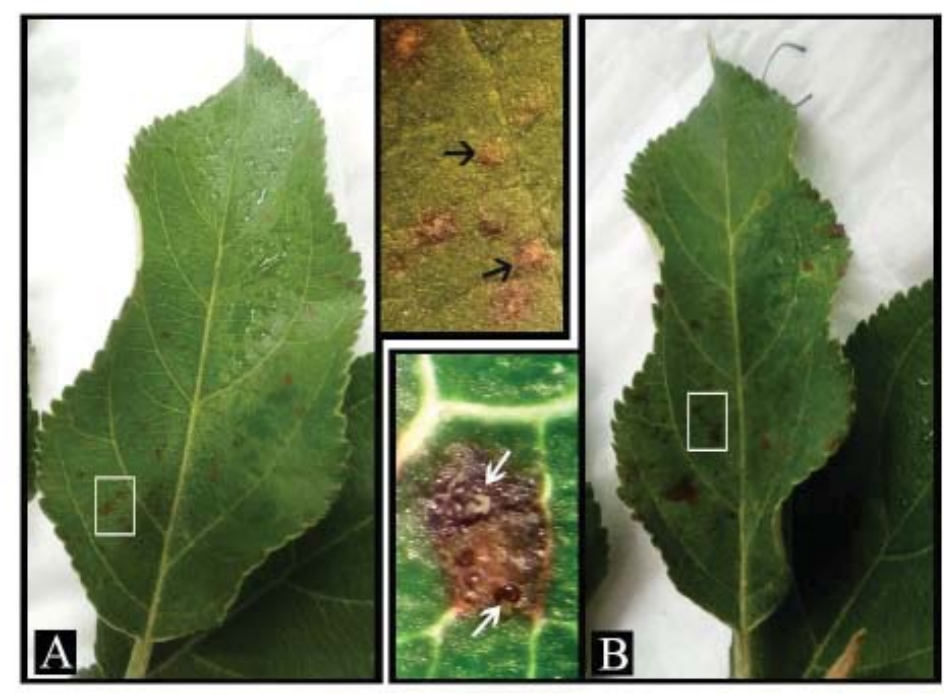

Figura 3: Pruebas de patogenicidad. A) Lesiones iniciales típicas de M. coronaria, de 3-6 mm de diámetro (15 dpi) sobre cv "Caricia". En el recuadro ampliado se muestra el detalle de las lesiones necróticas sin presencia de estructuras reproductivas visibles; B) Avance de lesiones luego de 21 dpi. En el recuadro ampliado se muestra el desarrollo de acérvulas sobre las lesiones. 
que el hongo necesita un período prolongado, con presencia de humedad elevada, para producir una infección exitosa. Esto explica parcialmente por qué la sintomatología generalmente comienza después de la lluvia y ocurre principalmente en los meses de noviembre y diciembre. Sharma et al., (29) tras ensayos en invernadero y campo en India determinaron que las infecciones por Marssonina se producen con temperaturas de $20^{\circ} \mathrm{C}$ y humedad de $100 \%$; con mojado en hojas por $40 \mathrm{hs}$, llegando a producir estas condiciones brotes epidémicos. Los mismos resultados fueron confirmados por Lee et al. (19).

Para cumplimentar con los postulados de Koch, el patógeno fue re-aislado de las lesiones producidas artificialmente; al comparar sus características morfométricas las mismas fueron coincidentes con las previamente descriptas para el género Marssonina.

Para nuestro conocimiento, esta es la primera vez que se registra a $M$. coronaria afectando hojas de manzano en Argentina. Los reportes que existen en el país para éste género refieren sólo a infecciones en estolones y pecíolos de frutilla, hoja de rosales, hojas y ramas de salicáceas $(4,5,9,34)$. A nivel mundial, Marssonina coronaria se registró afectando árboles de manzano en Japón (20), Canadá (23), Korea (19), India (27), Italia (31), China (16, 21), Panamá (25), Alemania, Suecia (14), Francia (18), Croacia (15) y Brasil (17) generando importantes problemas en la producción, afectando directamente el vigor de las plantas y la floración de años siguientes. Es para destacar que en Brasil la enfermedad se reporta para plantaciones de manzanos del cv. 'Eva'; éste es uno de los tres cultivares que también se encuentran implantados en la región Centro de Santa Fe. Junto a 'Caricia', 'Princesa', 'Condessa' y 'Annabella' son los que conforman las plantaciones que se registran en el centro norte entrerriano, San Luis del Palmar y Santa Rosa (Corrientes), Cerro Azul (Misiones), Colonia Caroya (Córdoba) y localidades de Catamarca, La Rioja, Tucumán y Buenos Aires, enfatizando la importancia de seguir profundizando en el estudio de ésta patología; especialmente en lo que hace a susceptibilidad varietal. A nivel mundial, Li et al. (22) trabajó evaluando la tolerancia a campo a M. coronaria y Alternaria alternata de 74 cultivares y portainjertos de manzano utilizados comúnmente en China reportando al $65 \%$ de éstos como altamente susceptibles. Por otra parte, Yin et al. (35) evaluaron 28 cultivares y 39 biotipos o especies de manzanos tradicionales en la zona de Shaanxi (China) mediante inoculaciones de hojas in vitro y en vivo demostrando diferencias en la susceptibilidad a M. coronaria. Hasta la fecha, no se registran informes sobre la evaluación e identificación de la resistencia a este patógeno fúngico en cultivares de manzano de bajos requerimientos de frío y portainjertos comúnmente utilizados en Argentina, lo que resalta la importancia de profundizar este tema.

\section{CONCLUSIONES}

Este estudio determinó a $M$. coronaria como la especie responsable de causar manchas foliares en manzanos de la Provincia de Santa Fe. En nuestro conocimiento, este resulta el primer reporte de la enfermedad afectando árboles de manzanos en el país. En función de los resultados obtenidos, se continuará trabajando para determinar las fuentes de sobrevivencia, la susceptibilidad de los diferentes cultivares de manzanos y se realizarán ensayos de sensibilidad a diferentes fungicidas para lograr establecer estrategias de manejo. 


\section{AGRADECIMIENTOS}

Este trabajo fue financiado por el Proyecto $\mathrm{CAI}+\mathrm{D}$ : Estudios etiológicos y epidemiológicos de la podredumbre amarga del manzano en la provincia de Santa Fe. Cod. Proyecto: 50020150100034LI. Res 128/16.

\section{BIBLIOGRAFIA}

1.- ALANIZ, S.; CUOZZO, V.; MARTÍNE, V.; STADNIK, M. Y MONDINO, P. 2018. Ascospore Infection and Colletotrichum Species Causing Glomerella Leaf Spot of Apple in Uruguay. Plant Pathol. J. : 35:2. https://doi.org/10.5423/PPJ.OA.07.2018.0145. pISSN 1598-2254 eISSN 2093-9280.

2.- BACK, C.G. Y H.Y. JUNG. 2014. Biological characterization of Marssonina coronaria infecting apple trees in Korea. Kor. J. Mycol. 42:183-190.

3.- BACK, C-G.; LEE, S-Y.; KANG, I-K.; YOON,T-M Y JUNG, H-Y. 2015. Occurrence and Analysis of Apple Blotch-like Symptoms on Apple Leaves. Kor. J. Hort. Sci. Technol. 33(3):429-434. ISSN 1226-8763. http://dx.doi.org/10.7235/hort.2015.14179

4.- BONACIC KRESIC, M.; Y CAMPAGNAC, N.A. 1982. Miscelánea $N^{\circ}$ 7: 1-61. En: Contribución al conocimiento de las enfermedades sobre distintos cultivos en el noreste argentino. - Eds. INTA EERA; ISSN 0325-7916.

5.- CABRERA, M. G.; ÁlVAREZ, R. E. Y SOSA DE CASTRO, N. T. 2006. Patologías que afectan a Rosa sp. en Corrientes, Argentina. - Comunicaciones Científicas y Tecnológicas. Universidad Nacional del Nordeste. http:/Documents/Downloads/patologias $\% 20$ rosa $\% 20$ corrientes.pdf. Acceso: mayo de 2019.
6.- CASTRO, D.; MICHELOUD, N.; BUTTARELLI, M.; ÁLVAREZ, N.; FAVARO, J.C Y GARIGLIO, N. 2015. Raleo químico con ácido naftalenacético, carbaryl y etefón en manzanos "Eva" y "Caricia”. Resultados preliminares. Revista FAVE - Ciencias Agrarias 14 (1). ISSN 1666-7719.

7.- DANSA, A. M. 2018. Perfil de mercados de manzana y pera. Ministerio de Agroindustria. Dirección de planeamiento y análisis d mercado. 14pp. https://www.agroindustria.gob.ar/ sitio/areas/ss_mercados_agropecuarios/areas/ frutas/_archivos/000030_Informes/100007_ Perfil\%20de\%20Mercado/000006_Perfil\%20 de\%20Manzanas $\% 20 y \% 20$ Peras.pdf

8.- FERNANDEZ, L.; ALANIZ, S.; MONDINO, P.; ROESCHLIN, R.; MAUMARY, R.; GARIGLIO, N. Y FAVARO, M. 2018. First Report of Colletotrichum siamense Causing Apple Bitter Rot in Central Argentina. Plan disease notes. Vol. 102:1. Page. 250. https://doi.org/10.1094/PDIS-07-17-1071-PDN

9.- FERNÁNDEZ VALIELLA, M.V. 1978. Vol II y III. Hongos en: Introducción a la Fitopatología. Colección Científica. INTA. Bs. As. 3ra. Ed.779 p.

10.- GARIGLIO, N.F.; BOUZO, C. Y TRAVADELO, M. (Editores). (2014). Cultivos Frutales y Ornamentales para zonas templado cálidas. Experiencias en la zona central de Santa Fe. Ediciones UNL, Santa Fe, 292 pp.

11.- GOYAL, A.; SHARMA, J. Y PHURAILATPAM, S. 2018. Studies on the Mode of Survival of Diplocarpon mali Causing Premature Leaf Fall of Apple. Int.J.Curr.Microbiol.App.Sci. 7(08): 2465-2474. doi: https:// doi.org/10.20546/ijcmas.2018.708.249

12.- HARADA, Y.; SAWAMURA, K. Y KONNO, K. 1974. Diplocarpon mali, sp. nov., the perfect state of apple blotch fungus Marssonina coronaria. Japanese Journal of Phytopathology 40(5):412-418 · DOI: 10.3186/ jjphytopath.40.412. 
13.- HEIDENREICH, C. Y TURECHEK, B. 21.- LI, D.; ZHAO, Z.; ZHAO, H.; HU, X.; 2001. Strawberry leaf scorch, Tree fruit \& Berry Pathology, New York State Agricultural Experiment Station, Geneva, New York. http:// www.nysaes.cornell.edu. Acceso: Abril 2019

14.- HINRICHS-BERGER, J. Y MÜLLER, G. 2013. Zum Auftreten von Marssonina coronaria an Apfel in Baden-Württemberg. Journal für Kulturpflanzen, 65, 347-350. DOI: 10.5073/JFK.2013.09.02

15.- IVIĆ, D.; SEVER, Z. Y TOMIĆ, Ž. 2017. Marssonina leaf blotch (Diplocarpon mali), a new disease of apple in Croatia. Glasilo biljne zaštite, 17(3), 323-328. http://D:/Documents/Downloads/Glasilo_3_2017_za_veb_ split_5.pdf. Acceso: Mayo 2019

16.- JIANG, H. S.; LENG, D. X.; QIN, S. M.; SUN, X. L.; GAO, Q. J. Y WAN, C. X. 2005. Out-break of Marssonina leaf blotch on apple and its control in Zhaoyuan. China Plant Protection, 25, 25-26.

17.- KRETZSCHMAR, A.; MARODIN, G. Y DUARTE, V. 2005. Ocorrência e intensidade de Marssonina mali em macieira cv. Eva nas condições da depressão central do Rio Grande do Sul. Revista de Ciências Agroveterinárias, Lages, v.4, n.2, p. 145-147. ISSN 1676-9732.

18.- LE CORRE, M. 2015. Attenion chute de feuilles! Reussier Fruit \& Legumes, 348, 48. https://abiodoc.docressources.fr/index.php?lvl=notice_display\&id=32121. Acceso: Junio 2018

19.- LEE, D.; BACK, C.; WIN, N.; CHOI, K.; KIM, K.; KANG, I.; CHOI, C.; YOON, T.; UHM, J. Y JUNG, H. 2011. Biological Characterization of Marssonina coronaria Associated with Apple Blotch Disease. Mycobiology 39(Vol 3): 200-205. http://dx.doi. org/10.5941/MYCO.2011.39.3.200.

20.- LEE, H. T. Y SHIN, H. D. 2000. Taxonomic studies on the genus Marssonina in Korea. Mycobiology, 28, 39-46. DOI: 10.1080/12298093.2000.12015720. LEI, Y. Y LIU, X. 2005. The study of regularity of apple early defoliation disease and its control by fungicide. Journal of Northwest Sci-tech University of Agriculture and Forestry (Natural Science Edition), 33, 76-80.

22.- LI, Y.; HIRST, P.; WAN, Y.; LIU, Y.; ZHOU, Q.; GAO, H.; GUO, Y.; ZHAO, Z.; WANG, L. Y HAN, M. 2012. Resistance to Marssonina coronaria and Alternaria alternate Apple Pathotype in the Major Apple Cultivars and Rootstocks Used in China. Hortscience 47(9):1241-1244. https://doi. org/10.21273/HORTSCI.47.9.1241

23.- PARMELEE, J. A. 1971. Marssonina leaf spot of apple. Canadian Plant Disease Survey, 57, 91-92.

24.- PHURAILATPAM, S.; SHARMA, J. N.; BRAKTA, A.; SHARMA, S. Y SHARMA, S. 2019. Morphological and Molecular Characterization of Marssonina coronaria (Ellis \& JJ Davis) JJ Davis Causing Premature Leaf Fall. Int. J. Curr. Microbiol. App. Sci, 8(6), 2762-2769. https://doi.org/10.20546/ijcmas.2019.806.333.

25.- PIEPENBRING, M.; CAMARENA, J.; CRUZ, D. Y GOMEZ, A. 2011. New records of pathogenic fungi on cultivated plants in Panama. Mycotaxon 115: 534-535.

26.- RISTA, L.; MAUMARY, R.; GARIGLIO, N. Y FAVARO, J. 2011. Botryosphaeria Dothidea (Moug.) afectando plantaciones de manzano y duraznero de la región centro - este de Santa Fe. Revista FAVE Ciencias Agrarias 10 (1-2). ISSN 1666-7719

27.-SHARMA, J. N. 2000. Marssonina blotch-a new disease of apple and its control. Indian Journal of Plant Protection, 28,100-101. 
28.- SHARMA, J. N. 2004. Biology, Epidemiology and Integrated Management of Marssonina Blotch Causing Premature Leaf Fall in Apple. Final report of ICAR Ad-hoc Research Project. Department of Mycology and Plant Pathology, UHF, Nauni, Solan, H.P. $41 \mathrm{p}$.

29.- SHARMA, N.; THAKUR, V.; MOHAN, J.; KHURANA, S. Y SHARMA, S. 2009. Epidemiology of Marssonina blotch (Marssonina coronaria) of apple in India. Indian Phytopathology 62 (3): 348-359.

30.- TAKAHASHI, S. Y SAWAMURA, K. 1990. In A. L. Jones \& H. S. Aldwinckle (Eds.), Compendium of apple and pear diseases (p. 33). St. Paul: American Phytopathological Society.

31.- TAMIETTI,G. Y MATTA, A. 2003. First report of leaf blotch caused by Marssonina coronaria on apple in Italy. Plant Disease, 87, 1005.

32.- WHITE, T.J.; BRUNS, T.; LEE, S.; Y TAYLOR, J. 1990. Amplification and direct sequencing of fungal ribosomal RNA genes for phylogenetics. En: Innis, M.A., Gelfand, D.H., Snisky, J.J., White, T.J., eds. PCR Protocols: a Guide to Methods and Applications. San Diego, CA, USA: Academic Press, 315-22.

33.- WÖHNER, T. Y EMERIEWEN, O. 2019. Apple blotch disease (Marssonina coronaria (Ellis \& Davis) Davis) - review and research prospects. Eur J Plant Pathol. 153:657-669. https://doi.org/10.1007/s10658-018-1590-9
34.- WRIGHT, E. R.; MORISIGUE, D. E.; RIVERA, M. C. Y PALMUCCI, H. E. 2001. Las enfermedades de los rosales en la república Argentina. - CETEFHO - JICA. Página/s: 47. - ISBN/ISSN: 987-98829-0-3.

35.- YIN, L.; LI, M.; KE, X.; LI, C.; ZOU, Y.; LIANG, D. Y MA, F. 2011. Evaluation of Malus germplasm resistance to marssonina apple blotch. Eur J Plant Pathol; 136:597602. DOI 10.1007/s10658-013-0190-y

36.- YIN, L.; WANG, P.; LI, M.; KE, X.; LI, C.; LIANG, D.; WU, S.; MA, X.; LI, C.; ZOU, Y. Y MA, F. 2013. Exogenous melatonin improves Malus resistance to Marssonina apple blotch. J. Pineal Res. 54:426-434. Doi:10.1111/jpi.12038

37.- ZHAO, H.; HUANG, L.; XIAO, C.L.; LIU, J.; WEI, J. Y GAO, X. 2010. Influence of culture media and environmental factors on mycelial growth and conidial production of Diplocarpon mali. Letters in Applied Microbiology. 639-644. ISSN 0266-8254. doi:10.1111/j.1472-765X.2010.02847.x 